\title{
Identifikasi Kandungan Hidrokuinon pada Krim Pemutih yang Beredar di Pasar Tradisional Wilayah Kabupaten Banjarnegara
}

\section{Identification of Hydroquinone Contents in Whitening Cream Distributed in Traditional Markets, Banjarnegara Region}

\author{
Sabtanti Harimurti ${ }^{1 *}$, Ika Sevi Deriyanti ${ }^{1}$, Hari Widada ${ }^{1}$, Pinasti Utami ${ }^{1}$ \\ ${ }^{1}$ Program Studi Farmasi, Fakultas Kedokteran dan Ilmu Kesehatan, Universitas Muhammadiyah Yogyakarta, \\ Jl. Brawijaya, Tamantirto, Kasihan, Bantul, Yogyakarta, Indonesia \\ *E-mail: sabtanti@umy.ac.id
}

Received: 21 Desember 2020; Accepted: 27 Juni 2021; Published: 30 Juni 2021

\begin{abstract}
Abstrak
Kosmetik yang dijual di pasaran banyak diminati oleh banyak wanita. Jenis kosmetik yang sering digunakan adalah krim pemutih. Krim ini dapat memberikan efek memutihkan pada kulit wajah sehingga dapat meningkatkan rasa percaya diri. Salah satu bahan yang memiliki khasiat memutihkan kulit dan sering ditambahkan pada krim pemutih adalah hidrokuinon. Bahan ini memiliki efek menghambat pembentukan melanin sehingga dapat memutihkan kulit. Penggunaan hidrokuinon tanpa pengawasan medis sudah tidak diperbolehkan karena dapat memberikan efek negatif seperti alergi, kulit menjadi merah dan rasa terbakar. Pada artikel ini akan dilaporkan hasil identifikasi kandungan hidrokuinon pada krim pemutih yang tidak bernomor izin edar dari BPOM (Badan Pengawas Obat dan Makanan) yang dipasarkan di wilayah Kabupaten Banjarnegara. Sampel diambil dari daerah Banjarnegara dan analisis dilakukan di Laboratorium Farmasi Universitas Muhammadiyah Yogyakarta. Identifikasi kandungan hidrokuinon dilakukan dengan metode KLT-Densitometri. Analisis kualitatif digunakan KLT, dimana fase diam yang digunakan adalah silika GF254 sedangkan fase gerak yang digunakan adalah toluen-asam asetat glasial pada perbandingan 8:2. Sampel ditotolkan menggunakan mikro syringe sebanyak $25 \mu \mathrm{L}$ setelah dilakukan ekstraksi. Selanjutnya untuk pembacaan bercak dilakukan dibawah sinar UV $254 \mathrm{~nm}$ yang kemudian dihitung nilai Rf-nya. Analisis kuantitatif dilakukan dengan densitometri dengan melihat luas area yang dihasilkan oleh bercak pada KLT. Dalam analisis ini, penghitungan kadar dilakukan dengan membandingkan luas area hidrokuinon sampel dengan luas area hidrokuinon kontrol positif dikalikan kadar hidrokuinon yang diketahui pada kontrol positif. Hasil analisis kualitatif menunjukan bahwa dari 21 sampel terdapat 6 sampel atau $28.57 \%$ sampel yang mengandung hidrokuinon. Analisis kuantitatif menunjukan kadar pada keenam sampel yang mengandung hidrokuinon yaitu sampel no $11: 7,12 \%$, sampel no $12: 3,69 \%$, sampel no 15 : $0,06 \%$, sampel no $16: 11,18 \%$, sampel no $18: 4,67 \%$, dan sampel no $19: 1,07 \%$. Berdasarkan hasil analisis tersebut terdapat beberapa sediaan yang mengandung hidrokuinon melebihi kadar yang aman yaitu 5\%, sehingga perlu dilakukan pengujian dan pengawasan secara regular dari lembaga yang berwenang agar krim pemutih wajah yang beredar aman untuk digunakan oleh masyarakat.
\end{abstract}

Kata Kunci: Densitometer, Hidrokuinon, Kosmetik, Krim Pemutih

\section{Abstract}

Cosmetics that are sold in the market are in great demand by many women. The type of cosmetics that is often used is a whitening cream. This cream can provide a whitening effect on facial skin so that it can increase self-confidence. One of the ingredients that have skin whitening properties and is often added to whitening creams is hydroquinone. This material has the effect of inhibiting the formation of melanin so that it can whiten the skin. The use of hydroquinone without medical supervision is not allowed because it can have negative effects such as allergies, skin redness, and a burning feeling. In this paper, we will report the identification results of the hydroquinone content in the whitening cream which is not a distribution license number from the BPOM (Indonesia Food and Drug Supervisory Agency) which is marketed in the Banjarnegara Region area. Samples were taken from the Banjarnegara area and the analysis was carried out at the Pharmacy Laboratory of the Universitas Muhammadiyah Yogyakarta. The analytical method used was the identification of the hydroquinone content carried out by the TLC-densitometry method. Qualitative 
analysis used TLC, where the stationary phase used was silica GF254 while the mobile phase used was toluene - glacial acetic acid at a ratio of 8: 2. Samples were dotted using a microsyringe of $25 \mu L$ after extraction. Furthermore, the spot identification was carried out under $254 \mathrm{~nm} U V$ light and then the $R f$ value was calculated. Quantitative analysis was used. It was carried out by densitometry by looking at the area produced by the spots on TLC. In this analysis, the level calculation was carried out by comparing the area of the hydroquinone sample with the area of the positive control hydroquinone multiplied by the known hydroquinone level in the positive control. The results of the qualitative analysis showed that of the 21 samples, there were 6 samples or $28.57 \%$ of the samples containing hydroquinone. Quantitative analysis shows the levels in the six samples containing hydroquinone, namely sample no.11: 7,12\%, sample no.12: 3.69\%, sample no.15: 0.06\%, sample no.16: 11.18\%, sample no.18: 4.67\%, and sample no.19: $1.07 \%$. Based on the results of the analysis, several preparations contain hydroquinone exceeding a safe level of $5 \%$, so it is necessary to regularly check testing and supervision from the authorized institution so that the circulating whitening cream is safe for use by the public.

Keywords: Cosmetics, Densitometer, Hydroquinone, Whitening Cream

\section{PENDAHULUAN}

Kosmetik adalah komponen bahan kimia yang digunakan untuk mempercantik wajah (Sarah, 2014). Sekarang ini, kosmetik menjadi kebutuhan primer terutama bagi wanita. Tingginya angka permintaan dan keinginan meningkatkan omzet yang memuaskan, sehingga beberapa produsen tidak mementingkan kualitas dan keamanan produk yang akan diedarkan kepada konsumen. Oleh karena itu, banyak dijumpai krim pemutih yang menggunakan bahan berbahaya (Azhara dan Khasanah, 2011). Beberapa peneliti melaporkan tentang pengunaan hidrokuinon dalam pemutih wajah. Nurfitriani dkk (2015) melaporkan adanya penggunaan hidrokuinon dalam pemutih wajah yang beredar di daerah Bandung. Selain itu juga ditemukan penggunaan hidrokuinon pada krim pemutih wajah di negara Iran (Elferjani et al., 2017). Penelitian yang dilakukan oleh 12 dermatologist pada tahun 1977-1983 di Amerika Serikat menyatakan bahwa diperkirakan 713 pasien dari 13.216 pasien mengalami dermatitis kontak karena penggunaan kosmetik (Adams dan Mibach, 1985).

Kosmetik ilegal terutamanya pemutih wajah umumnya mengandung dua bahan kimia berbahaya yaitu merkuri dan hidrokuinon. Tujuan penggunaan bahan kimia tersebut adalah menjadikan kulit wajah mulus (Syafnir dan Putri, 2011) dan memutihkan wajah dalam waktu singkat (Rasyid et al.,
2015). Penggunaan bahan kimia merkuri pada krim pemutih memberikan wajah menjadi lebih putih, bersih, halus, dan dapat menghilangkan jerawat serta dapat mengecilkan pori-pori (Mayaserli dan Sasmita, 2016). Hidrokuinon dalam kosmetik digunakan untuk menghilangkan bercakbercak hitam pada wajah. Hidrokuinon dengan kadar yang tinggi dapat menimbulkan efek samping yang tidak diinginkan seperti iritasi kulit, kulit menjadi merah dan rasa terbakar serta tedapat bercak-bercak pada wajah (Ibrahim et al., 2004).

Penggunaan hidrokuinon pada krim pemutih wajah hanya diperboleh tidak melebihi $0.02 \%$ pada kuku buatan dan penggunaan hidrokuinon pada pemutih wajah sudah tidak diperbolehkan sejak tahun 2008 (BPOM, 2011; BPOM, 2015). Badan kesehatan Belanda dan Food Drug Administration (FDA) mengeluarkan larangan penggunaan hidrokuinon dalam sediaan pemutih wajah karena dampak yang ditimbulkan sangat berbahaya seperti kanker (Tsai dan Hantash, 2008).

Hidrokuinon dikategorikan bahan berbahaya bagi kesehatan dengan kadar lebih dari 5\% karena dapat menyebabkan pengelupasan kulit bagian luar dan dengan pemakaian jangka panjang dapat menyebabkan penghambatan pembentukan melanin yang membuat kulit nampak putih (ochronosis) (BPOM, 2007). Selain itu, hidrokuinon dapat menyebabkan kelainan 
ginjal (nephropathy), kanker darah (leukimia), kanker sel hati (hepatocelluler adenoma). Oleh karena itu, hidrokuinon merupakan obat keras yang penggunaanya harus berdasarkan resep dokter (James, 2006).

Berdasarkan dari latar belakang yang sudah disebutkan di atas dan dengan semakin maraknya peredaran perdagangan kosmetik ilegal di pasaran bebas, maka perlu dilakukan peneltian ini untuk mengevaluasi banyaknya kosmetik yang mengandung hidrokuinon dengan konsentrasi lebih dari yang diperbolehkan. Penelitian dimulai dari daerah Banjarnegara yang merupakan daerah asal dari peneliti, yang kemungkinan besar akan dilakuan juga untuk daerah lainnya. Ini dilakukan untuk memberikan informasi kepada masyarakat luas agar lebih berhati-hati dalam memilih kosmetik, terutamanya krim pemutih wajah.

\section{METODE PENELITIAN}

Alat

Alat yang digunakan pada penelitian ini adalah gelas ukur $50 \mathrm{~mL}$ (Pyrex $\left.{ }^{\circledR}\right)$, labu ukur $25 \mathrm{~mL}\left(\right.$ Pyrex $\left.^{\circledR}\right)$, beaker gelas $\left(\right.$ Pyrex $\left.^{\circledR}\right)$, pipet ukur $10 \mathrm{~mL}\left(\right.$ Pyrex $\left.^{\circledR}\right)$, pipet volume $2 \mathrm{~mL}$ $\left(\right.$ Pyrex $\left.^{\circledR}\right)$, pipet volume $5 \mathrm{~mL}\left(\right.$ Pyrex $\left.^{\circledR}\right)$, pipet tetes, propipet, sendok pengaduk, kertas saring, timbangan digital, waterbath, plat KLT, mikro syringe, bejana kromatografi (chamber), lampu UV, dan densitometer (Camag TLC Scanner 4).

\section{Bahan}

Bahan yang digunakan pada penelitian ini adalah Standar hidrokuinon (BPOM), krim pemutih (krim yang digunakan berasal dari beberapa pasar tradisional di Kabupaten Banjarnegara), $\mathrm{HCl} 4 \mathrm{~N}$ (Merck $^{\circledR}$ ), etanol $\left(\right.$ Brataco $\left.^{\circledR}\right)$, natrium sulfat $\left(\right.$ Merck $\left.^{\circledR}\right)$, fase diam (silika gel GF 254) $\left(\right.$ Merck $\left.^{\circledR}\right)$, fase gerak toluen $\left(\right.$ Merck $\left.^{\circledR}\right)$ :asam asetat glasial $\left(\right.$ Brataco $\left.^{\circledR}\right)(80: 20)$ dan aquades $\left(\right.$ Brataco $\left.^{\circledR}\right)$.

\section{Prosedur Kerja \\ Preparasi Sampel Uji}

Sebanyak 1,25 gram sampel krim pemutih ditimbang kemudian dimasukkan ke dalam beaker gelas. Bahan kemudian ditambah 3 tetes $\mathrm{HCl} 4 \mathrm{~N}$ dan $5 \mathrm{~mL}$ etanol, kemudian dipanaskan di atas waterbath dengan suhu $60^{\circ} \mathrm{C}$ selama 10 menit sambil diaduk (Siddique et al., 2012). Masing-masing sampel yang telah dipanaskan disaring dan dimasukkan ke dalam labu ukur $25 \mathrm{~mL}$. Penyaringan dilakukan pada kertas saring yang ditambahkan natrium sulfat di atasnya untuk mengangkat lemak. Selanjutnya ditambahkan etanol sampai garis tanda pada masing-masing sampel yang telah disaring dan dihomogenkan dengan cara dikocok.

\section{Pembuatan Fase Gerak}

Toluen diambil dengan menggunakan pipet ukur sebanyak $8 \mathrm{~mL}$ kemudian dimasukkan pada beaker gelas. Asam asetat glasial diambil sebanyak $2 \mathrm{~mL}$ dimasukkan pada beaker gelas yang berisi toluen. Campuran dihomogenkan dan dimasukkan dalam chamber. Kertas saring dimasukkan ke dalam chamber untuk mengetahui bahwa fase gerak telah jenuh memenuhi chamber yang bisa diidentifikasi dari fase gerak yang telah naik ke atas pada kertas saring.

\section{Penotolan pada plat KLT}

Larutan standar hidrokuinon $0,1 \%$, larutan kontrol positif (komersial krim pemutih) dan larutan sampel ditotolkan di atas plat KLT dengan volume penotolan $25 \mu \mathrm{L}$ menggunakan microsyringe.

\section{Evaluasi Keberadaan Hidrokuinon dalam Sampel}

Penentuan Rf hidrokuinon pada penelitian ini didasarkan pada penelitian terdahulu oleh Ningsih (2009). Setelah itu, dibandingkan dengan standar hidrokuinon dari BPOM.

\section{Analisis Kuantitatif Krim Pemutih Dengan} Metode Densitometer

Plat KLT yang telah dibaca pada sinar ultraviolet dan terdapat sampel yang mengandung hidrokuinon dimasukkan pada alat pembaca densitometer. Bercak yang terbentuk dilihat pada panjang gelombang 254 nm. Luas area di bawah kurva (AUC) yang 
dihasilkan oleh kontrol positif digunakan sebagai dasar perhitungan kadar hidrokuinon pada sampel. Kadar hidrokuinon pada sampel dihitung dengan rumus perhitungan sebagai berikut:

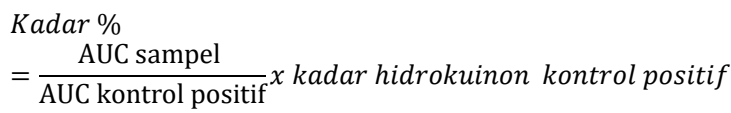

\section{HASIL DAN PEMBAHASAN}

Pada penelitian ini metode analisis kualitatif yang digunakan untuk menentukan ada atau tidaknya kandungan hidrokuinon pada krim pemutih wajah adalah KLT. Pembacaan bercak dilakukan di bawah sinar UV pada panjang gelombang $254 \mathrm{~nm}$ (Ningsih, 2009). Hasil pembacaan bercak plat KLT dapat dilihat pada Gambar 1, 2, dan 3. Metode KLT merupakan metode yang sederhana dan cepat untuk memisahkan senyawa pada suatu campuran (Day dan Underhood, 2002). Sampel dikatakan mengandung hidrokuinon apabila tinggi bercak sampel sejajar dengan tinggi bercak baku standar dan kontrol positif. Dalam penelitian ini, baku standar yang digunakan adalah hidrokuinon dan kontrol positif yang digunakan adalah krim pemutih komersial yang memiliki nomor izin edar dari BPOM yang dijual di pasaran dan diketahui mengandung $2 \%$ hidrokuinon. Perhitungan Rf dapat dilakukan dengan menghitung jarak yang ditempuh sampel atau larutan yang ditotolkan pada plat KLT dibandingkan dengan jarak fase gerak.

Berdasarkan hasil analisis kualitatif menggunakan KLT dari 21 sampel krim pemutih terdapat 6 sampel atau 28,57\% sampel yang mengandung hidrokuinon (Gambar 1, 2 dan 3). Nilai Rf standar hidrokuinon, kontrol positif dan keenam sampel mempunyai nilai $\mathrm{Rf}$ yang mirip yang sebesar $\pm 0,17$. Adapun sampel yang mempunyai nilai $\mathrm{Rf}$ mirip dengan baku standar hidrokuinon dan kontrol positif adalah sampel nomor $11,12,15,16,18$ dan 19 seperti terlihat pada Gambar 1, 2 dan 3.

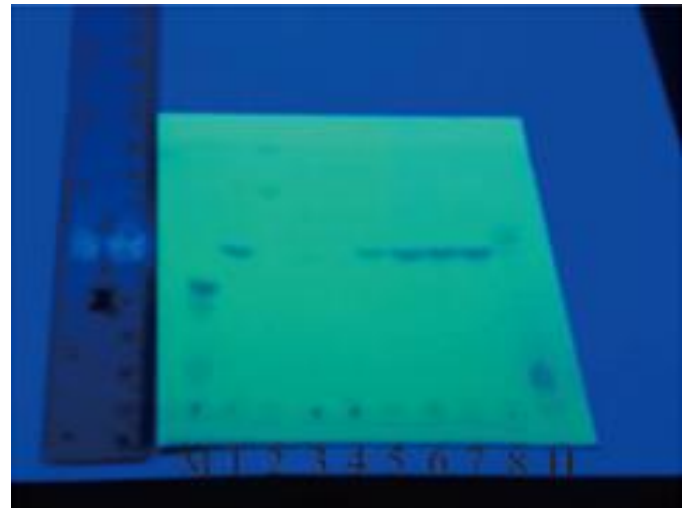

Gambar 1. KLT sampel 1-8. (M) Kontrol Positif; (1) Sampel 1; (2) Sampel 2; (3) Sampel 3; (4) Sampel 4; (5)Sampel 5; (6) Sampel 6; (7) Sampel 7; (8) Sampel 8; dan (H) Standar Hidrokuinon.

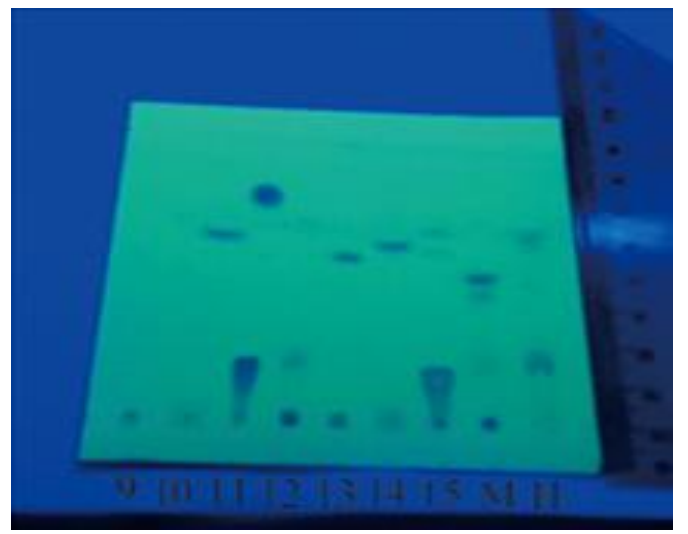

Gambar 2. KLT untuk sampel 9-15. (9) Sampel 9; (10) Sampel 10; (11) Sampel 11; (12) Sampel 12; (13) Sampel 13; (14) Sampel 14; (15) Sampel 15; (M) Kontrol Positif; dan (H) Standar Hidrokuinon

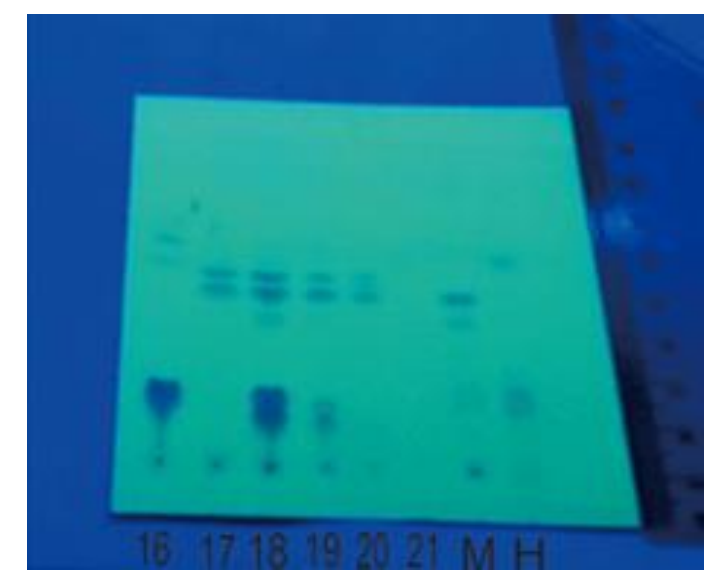

Gambar 3. KLT untuk sampel 16-21. (16) Sampel 16; (17) Sampel 17; (18) Sampel 18; (19) Sampel 19; (20) Sampel 20; (21) Sampel 21; (M) Kontrol Positif; dan (H) Standar Hidrokuinon 
Dalam penelitian ini, plat KLT yang positif menunjukkan adanya hidrokuinon dalam sampel kemudian dianalisis menggunakan densitometer untuk mengetahui seberapa besar kandungan hidrokuinon pada keenam krim pemutih tersebut di atas. Penggunaan metode KLT-Densitometri untuk analisis kuantitatif hidrokuinon didasarkan pada ide penelitian Wulandari et al. (2013) yang menyatakan bahwa metode KLTDensitometri memberikan hasil analisis yang selektif, spesifik, linier, presisi dan akurat pada penetapan kadar teofilin dan efedrin hidroklorida secara simultan pada sediaan tablet. Hal serupa disampaikan oleh Kurunawati (2013) yang menyatakan bahwa metode KLT-Densitometri dapat digunakan untuk analisis kualitatif dan kuantitatif campuran deksametason dan deksklorfeniramin maleat dalam kaplet. Namun pada penelitian ini, data validasi metode belum tersedia, karena tujuan awal

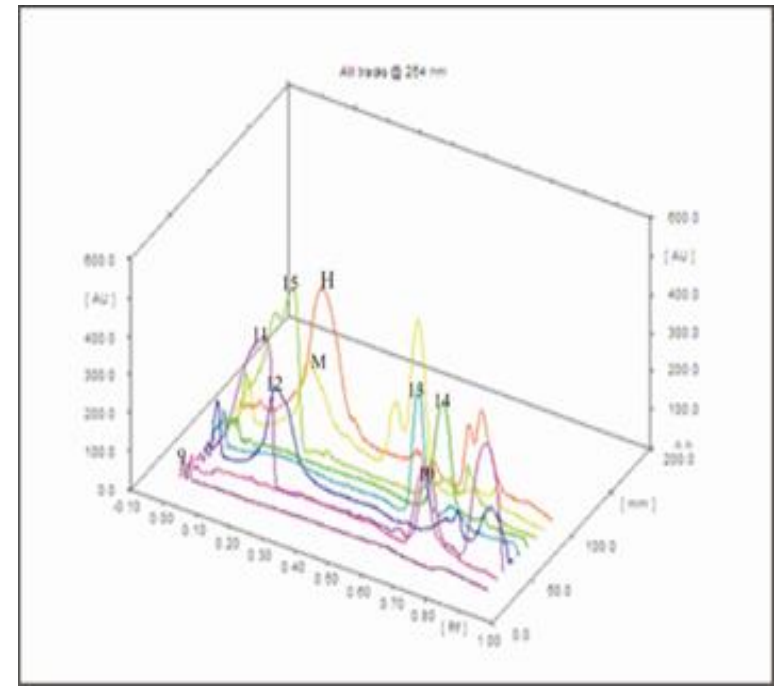

(a) dari penelitian ini adalah untuk mengidentifikasi kandungan hidrokuinon pada krim pemutih yang dijual bebas di pasaran. Validasi metode KLT-Densitometri untuk analisis kualitatif dan kuantitatif hidrokuinon masih perlu dilakukan untuk tahap selanjutnya. Oleh karena itu, dalam penelitian ini, analisis kuantitatif yang dilakukan adalah hanya melakukan perhitungan kadar relatif hidrokuinon yang dihtung dengan cara membandingkan luas area yang diperoleh dari sampel dibandingkan dengan luas area yang diperoleh dari kontrol positif dikalikan dengan konsentrasi hidrokuinon yang sudah diketahui dalam kontrol positif. Hal ini dilakukan karena kontrol positif melalui semua tahap preparasi yang dilalui juga oleh sampel. Hasil analisis menggunakan densitometer dapat dilihat pada Gambar 4. Hasil perhitungan kadar hidrokuinon menggunakan cara tersebut di atas dapat dilihat pada Tabel 1 .

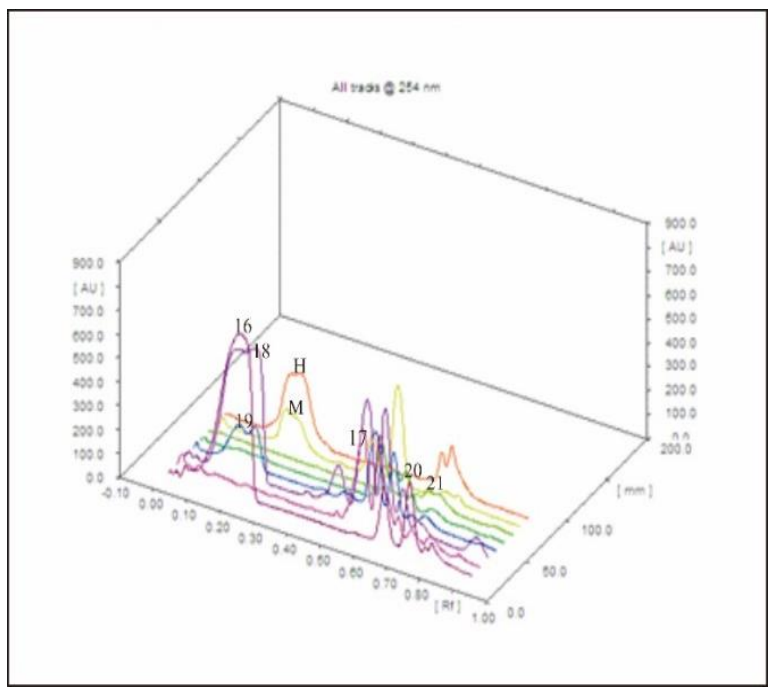

(b)

Gambar 4. (a) Densitometer Kromatogram Untuk Sampel 9 - 15. (9) Sampel 9; (10) Sampel 10; (11) Sampel 11; (12) Sampel 12; (13) Sampel 13; (14) Sampel 4; (15) Sampel 15; (M) Kontrol Posisitif; (H) Standar Hidrokuinon, (b) Densitometer Kromatogram Untuk Sampel 16 - 21. (16) Sampel 16; (17) Sampel 17; (18) Sampel 18; (19) Sampel 19; (20) Sampel 20; (21) Sampel 21; (M) Kontrol posisitif; (H) Standar Hidrokuinon 
Tabel 1. Hasil pemeriksaan secara kuantitatif kandungan hidrokuinon pada krim pemutih

\begin{tabular}{ccccc}
\hline No & Kode Sampel & Nilai Rf & Luas Area & Konsentrasi (\%) \\
\hline 1 & 1 & - & - & - \\
2 & 2 & - & - & - \\
3 & 3 & - & - & - \\
4 & 4 & - & - & - \\
5 & 5 & - & - & - \\
6 & 6 & - & - & - \\
7 & 7 & - & - & - \\
8 & 8 & - & - & - \\
9 & 9 & - & - & - \\
10 & 10 & - & - & - \\
11 & 11 & 0,17 & 31148,0 & 7,12 \\
12 & 12 & 0,17 & 16156,8 & 3,69 \\
13 & 13 & - & - & - \\
14 & 14 & - & - & - \\
15 & 15 & 0,16 & 282,1 & 0,06 \\
16 & 16 & 0,17 & 48911,0 & 11,18 \\
17 & 17 & - & - & - \\
18 & 18 & 0,17 & 20440,0 & 4,67 \\
19 & 19 & 0,16 & 4668,9 & 1,07 \\
20 & 20 & - & - & - \\
21 & 21 & - & - & - \\
22 & Kontrol positif & 0,17 & 8748,8 & 2,00 \\
23 & Standar Hidrokuinon & 0,17 & 18436,1 & 0,10 \\
\hline
\end{tabular}

Hasil analisis kuantitatif diperoleh kadar relatif pada masing-masing sampel yang mengandung hidrokuinon adalah sebagai berikut; sampel no $11: 7,12 \%$, sampel no 12 : $3,69 \%$, sampel no $15: 0,06 \%$, sampel no 16 : $11,18 \%$, sampel no $18: 4,67 \%$, dan sampel no $19: 1,07 \%$. Hasil yang diperoleh ini jauh lebih besar dari apa yang dilaporkan oleh Elferjani (2017) yang meneliti kandungan hidrokuinon pada krim pemutih wajah yang dijual di apotek dan yang dibuat manual yang beredar di Iran. Dilaporkan bahwa kadar hidrokuinon pada sedian pemutih wajah yang diteliti sebesar 0,008\%-0,210\% dari 13 sampel yang diteliti. Menurut BPOM (2007), kadar aman hidrokuinon pada sediaan adalah tidak lebih dari 5\%. Berdasarkan hal ini beberapa sediaan krim pemutih wajah yang beredar di daerah
Banjarnegara mengandung hidrokuinon melebihi kadar aman, oleh karena itu perlu dilakukan pengujian dan pengawasan oleh pihak yang berwenang agar sediaan krim pemutih wajah yang beredar aman untuk digunakan oleh masyarakat.

\section{KESIMPULAN}

Berdasarkan hasil penelitian yang telah dilakukan pada krim pemutih yang beredar di pasaran wilayah Kabupaten Banjarnegara, maka dapat disimpulkan bahwa dari 21 sampel krim pemutih terdapat 6 sampel atau $28,57 \%$ sampel yang mengandung hidrokuinon. Dari ke 6 sampel yang mengandung hidrokuinon diperoleh kadar terendah adalah $0,06 \%$ dan tertinggi $11,18 \%$. 


\section{Daftar Pustaka}

Adams, R.M, and Maibach, H.I. 1985. A five-year study of cosmetic reactions, Journal American Academic Dermatologic 13: 1062-1069.

Azhara, K.N. 2011. Waspada bahaya kosmetik, Flashbooks, Jogjakarta.

Badan Pengawas Obat dan Makanan. 2007. Kosmetik mengandung bahan berbahaya dan zat warna yang dilarang : keputusan kepala Badan Pengawas Obat dan Makanan Republik Indonesia No HK.00.01.432.6081.

Day, R.A., Underwood, A.L. 2002. Analisis kimia kuantitatif edisi keenam, Erlangga, Jakarta.

Elferjani, H.S, Ahmida, N.H.S, and Ahmida, A. 2017. Determination of hydroquinone in some pharmaceutical and cosmetic preparation by spectrophotometric method, International Journal of Science and Research (IJSR), 6(7): 2219-2224.

Ibrahim, S., Damayanti, S., Riani, Y. 2004. Penetapan dan keseksamaan metode kolorimetri menggunakan pereaksi floroglusin untuk penetapan kadar hidrokuinon dalam krim pemucat, Acta Pharmaceutica Indonesia, Vol 29.

James, J.A. 2006. Skin lightening and depigmenting agent, Journal of The European Academy of Dermatology and Veneurologi, Medical Centre Department Dermatology University Pennsylvania.

Karunawati, M.S. 2013. Validasi metode kromatografi lapis tipis densitometri pada penetapan kadar campuran deksametason dan deksklorfeniramin maleat dalam kaplet, Skripsi, Fakultas Farmasi Universitas Sanata Dharma, Yogyakarta.

Mayaserli, D.P., dan Sasmita, W. 2016. Pemeriksaan kadar merkuri dan keluhan kesehatan dalam darah wanita pemakai krim pemutih dengan metode inductively coupled plasma, Jurnal of Sainstek 8: 159-165.

Ningsih, A.U. 2009. Identifikasi hidrokuinon dalam krim pemutih, Skripsi, Fakultas Matematika dan Ilmu Pengetahuan Alam Universitas Sumatra Utara, Medan.

Nurfitriani, S., Hadisoebroto, G., Budiman S. 2015. Analisis penetapan kadar hidrokuinon pada kosmetik krim pemutih yang beredar di beberapa tempat di kota Bandung, Prosiding SNIFA UNJANI 2015.

Peraturan Kepala Badan Pengawas Obat dan Makanan. 2011. Persyaratan teknis bahan kosmetika, Jakarta (ID): Nomor HK.03.1.23.08.11.07517 Tahun 2011.

Peraturan Kepala Badan Pengawas Obat Dan Makanan. 2015. Persyaratan teknis bahan kosmetika, Jakarta (ID): Nomor 18 Tahun 2015.

Rasyid, R., Susanti, E., dan Azhar, R. 2015. Pemeriksaan kualitatif hidrokuinon dan merkuri dalam krim pemutih, Jurnal Farmasi Higea 7: 63-73.

Sarah, K.W. 2014. Analisis hidrokuinon dalam sediaan krim malam cw 1 dan cw 2 dari klinik kecantikan N dan E di kabupaten Sidoarjo, Jurnal Ilmiah Mahasiswa Universitas Surabaya 3: 1-27. 
Siddique, S., Parveen, Z., Ali, Z., and Zaheer, M. 2012. Qualitative and quantitative estimation of hydroquinone in skin whitening cosmetics, Journal Of Cosmetics, Dermatological Sciences and Applications 2: 224-228.

Syafinir, L, dan Putri, A.P. 2011, Pengujian kandungan merkuri dalam sediaan kosmetik dengan spektrofotometri serapan atom, Prosiding SNAPP 2011: Sains, teknologi dan kesehatan 2: 71-78.

Tsai, T.C., and Hantash, B.M. 2008, Cosmeceutical agents: a comprehensive review of the literature, Clinical Medicine Insigths:Dermatology 1: 1.

Wulandari, L., Retnaningtyas, Y., Mustafidah, D. 2013. Pengembangan dan validasi metode kromatografi lapis tipis densitomeri untuk penetapan kadar teofilin dan efedrin hidroklorida secara simultan pada sediaan tablet, JKTI 15: 15-21. 